\title{
ANALYSIS OF SETTLEMENT OF FOUNDATION PLATES BY FINITE DIFFERENCE METHOD
}

\author{
Maja Prskalo \& Anton Vrdoljak
}
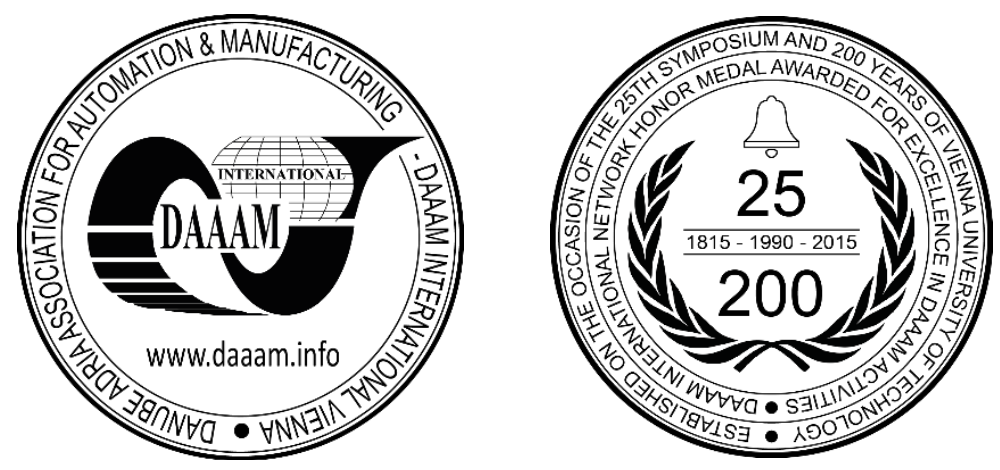

This Publication has to be referred as: Prskalo, M[aja] \& Vrdoljak, A[nton] (2016). Analysis of Settlement of Foundation Plates by Finite Difference Method, Proceedings of the 27th DAAAM International Symposium, pp.08540859, B. Katalinic (Ed.), Published by DAAAM International, ISBN 978-3-902734-08-2, ISSN 1726-9679, Vienna, Austria

DOI: $10.2507 / 27$ th.daaam.proceedings. 123

\begin{abstract}
This paper provides an analysis of settlement of foundation plates using finite difference method, and is designed in the aim to prove how this method, implemented in our Matlab program code, will give results similar to those obtained with the finite element method, and to show that plate' settlements are less dependent on the change of modulus of soil reaction.
\end{abstract}

Keywords: foundation plate; finite difference method; settlement; modulus of soil reaction; Matlab.

\section{Introduction}

To do the high-quality calculation and reliable performance of the foundations of the building, it is necessary, among other things, to resolve the interaction of the object, foundations and soil during all phases of construction. In all these cases, if the foundation feet are too close, or if they overlap, or if we have to reduce the differential settlement, we have to determine for the foundation plates. The mechanical properties of the soil are very complex and the solution to the problem of interaction between foundation soil with the structural elements requires certain simplifications, because without them the problem will be unsolvable or economic unprofitable. With this in mind, the greatest number of solutions is developed for the soil as linearly elastic, homogenous and isotropic half-space [5]. These simplifications and the improvement of the computer technology allow us the use of the numerical methods for calculation of the stress as well as for settlement of foundation plates [4]. In this paper we will use finite difference method (FDM), the oldest numerical method for solving partial differential equations [3], [4].

\section{Previous research}

Various theoretical and numerical procedures are developed to obtain approximate solutions of real distribution of stresses in a structure-soil interface. A practically reasonable approximation of the actual state is achieved by developing numerical procedures and thoroughly investigating deformation properties of soil [7].

The problem of numerical resolution of partial differential equations, or finding and/or improving the algorithms for solving them is studied in numerical analysis - a branch of numerical mathematics. The most famous numerical method for solving such problems is the finite difference method (or mesh method) which idea is to approximate the derivatives 
of function (of one or more variables) with the divided differences. There are several other methods in use, such are collocation method, Galerkin method, Ritz method and finite element method.

Finite difference method replaces the main differential equation with the system of algebraic equations that links shifts of observed points relative to neighbouring points. These points are distributed in a $\mathrm{grid} / \mathrm{mesh}$ of the surface of the plate. The method was first formulated (introduced) by Allen and Severn, and is described in different publications.

\section{Numerical method - finite difference method}

Finite difference method replaces the main differential equation with the system of algebraic equations that links shifts of observed points relative to neighbouring points. It is placed in every point of the grid/mesh on the surface of the plate, thus a system of algebraic equations is formed, the system based on a rectangular coordinate system, and on a load, as well as on the physical and elastic constants of the loaded plate. This load-deformation equation establishes a linear relationship between the load at the focal point and the unknown value of the deformation of the plate at that point, but in the other active points too, so by solving these equations the approximate values of the deformation of the plate in the active points of the mesh are obtained. Refinement of the mesh will result with increasing of the order for matrix of the system, and with growing of the complexity for the algorithm which would be almost impossible to solve without using a computer [1].

Figure bellow is showing a division/distribution of the surface of the plate with grid lines, what is resulting with rectangular elements of the grid/mesh. In direction, we are having a interval between grid lines $h$, and $r h$ in $x$ direction. Places of intersecting for two grid lines we will call grid/mesh points. Some of them are marked with letters (N, E, S, $\mathrm{W}, \ldots)$ and are called active points, and a central/middle point of an active group of points is called the focal point (Z). To simplify the writing of equations, the marks of the active grid points are used also as the size of settlement $w$, and the middle plains are observed in specific grid point on the plate.
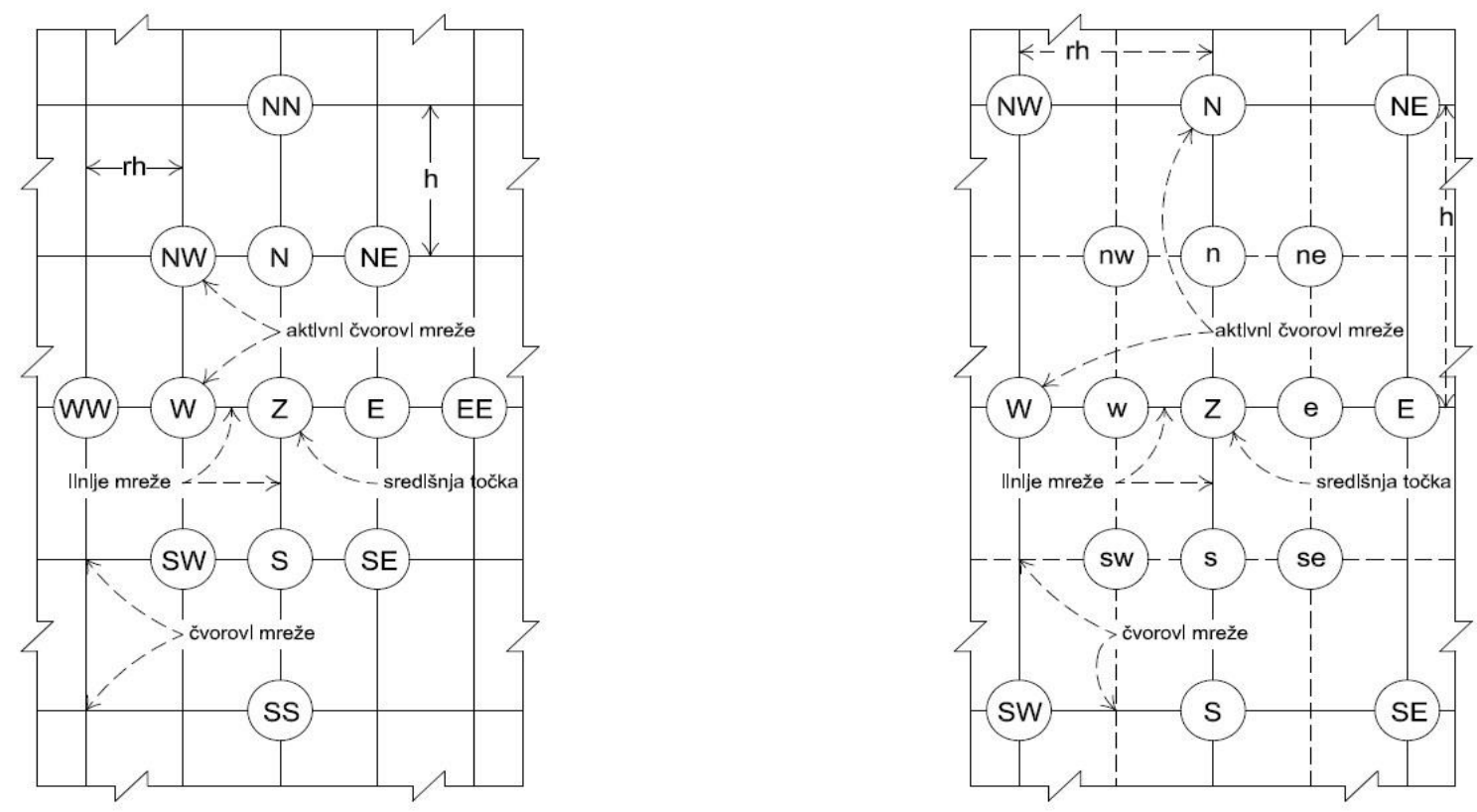

Fig. 1. The system of marking for the grid points

By using a standard procedure of finite difference method, then by including a value of deflection of the plate in the form of designation of active grid points and finally by arranging, the Lagrange differential equation will translate into the following equation:

$$
\begin{aligned}
\frac{1}{r^{4}}(W W-4 W+ & 6 Z-4 E+E E)+\frac{2}{r^{2}}(N W-2 N+N E-2 W+4 Z-2 E+S W-2 S+S E) \\
+ & (N N-4 N+6 Z-4 S+S S)=\frac{P_{Z} h^{2}}{r D}
\end{aligned}
$$

Equation (1) is the basic load-deformation relation to any internal active point. Next, this general form of the equation is being used for special cases which involving the boundary cases, as well as for all relations connecting the deformation 
of the plate with the loads, momentums, reactions and shear [2]. Essentially, this load-deformation equation establishes a linear relationship between the load at the focal point and the unknown value of the deformation of the plate at that point, but in the other active points too, so by solving these equations the approximate values of the deformation of the plate in the active points of the mesh are obtained.

\section{Determination for the modulus of soil reaction}

The foundation of the building/object is defined as an integral part of the structure that is in direct contact with soil or rock massif and which receives and transmits the load from the building to the soil/ground or rock massif. Due to object's load the soil is being deformed, and while deformed it returns the reactive load to the building structure. The soil and the structure of the building are being deformed together, which is why it is necessary to consider projecting/designing the foundations together with the construction of the building and vice versa. Their mutual consideration and design leads to more favourable technical and economic solutions for entire building/object [8]. During the analysis of the foundation plate, the soil can be observed in two ways:

- as a group of springs, according Winkler's theory;

- as a continuum, which is usually observed as elastic half-space.

The modulus of soil reaction can be determined in the following ways:

- by using circular plate;

- by using a table of typical values and correlations;

- by calculating of settlement.

The usual way of obtaining for modulus of soil reaction is by applying loads to the soil through a circular plate with a diameter of $30 \mathrm{~cm}$. The disadvantage of this method is regarding the load, but only for the layer of lower thickness (lower in comparison to the layer loaded with the foundation plate). The modulus of soil reaction can also be estimated on the basis of predicted settlement for real foundation. In this case it can be assumed that the foundation is solid and under pressure corresponding to the total load on the foundation. The settlement is projected by standard methods of soil mechanics. In this case, the modulus of soil reaction we can calculate as follows:

$$
k=\frac{\bar{q}}{\bar{w}}
$$

where $\bar{q}$ is average pressure, and $\bar{w}$ is settlement for solid foundation.

This procedure can take into account the different layers exposed to different levels of stress, what was not possible in the previous known methods. In addition, thanks to short-term and long-term predictions for the settlement, we are able to get modules for short-term and long-term analysis of the behaviour of the foundation, taking into account both, the consolidation and creep of soil. It is difficult to find a relation between $k$ and Young's modulus for elastic half-space because the answer depends on the stiffness of the foundation itself. Such a relation is obtained by equating the settlement of solid plate in homogeneous elastic half-space, with the settlement of the same plate on Winkler's springs. It follows:

$$
k=\frac{1}{B \cdot I_{B}}\left(\frac{E}{1-v^{2}}\right)
$$

The modulus of soil reaction is not constant value, but depends on the quantity of the load ( $p$ ), and on the shape and the size of the loaded test plane. Terzaghi is suggesting the values for the modulus of soil reaction $\left(k_{1}\right)$, for test surface $30 \mathrm{~cm} \times 30 \mathrm{~cm}$ and for different types of soil and its compaction (1955), which are given in table (1). In a case of larger test areas, Terzaghi is proposing corrections in the form of [6]:

- for incoherent soil:

$$
k=k_{1}\left(\frac{B^{\prime}+1}{2 B^{\prime}}\right)^{2}
$$

- for coherent soil:

$$
k=\frac{k_{1}}{B}
$$


where

$B^{\prime}=B / 30.3$

and $B$ is width of the foundation $(\mathrm{cm})$.

\begin{tabular}{|l|l|l|l|l|}
\hline \multicolumn{2}{|l|}{ Sand } & Incoherent & $\begin{array}{l}\text { Half- } \\
\text { coherent }\end{array}$ & Coherent \\
\hline 1. & Dry or wet & $0.6-1.9$ & $1.9-9.6$ & $9.6-32$ \\
\hline 2. & $\begin{array}{l}\text { Partially } \\
\text { sunken }\end{array}$ & 1.3 & 4.2 & 16 \\
\hline 3. & Sunken & & & \\
\hline \multicolumn{2}{|l|}{ Clay } & 0.8 & 2.6 & 9.6 \\
\hline 1. & $q_{u}\left(\mathrm{kN} / \mathrm{m}^{2}\right)$ & Consistency & \multicolumn{2}{l|}{} \\
\cline { 2 - 5 } 2. & Limits & Stiff & Very stiff & Solid \\
\hline 3. & $\begin{array}{l}\text { Partially } \\
\text { sunken }\end{array}$ & $100-200$ & $200-400$ & $>400$ \\
\hline
\end{tabular}

Table 1. Examples of calculations for selected modulus of soil reaction

The following examples will demonstrate the results of calculations for foundation foot and foundation plate for different types of soil, with an accent on their maximum settlements. In these calculations we used the modified program code, which is initially developed by Salar Delaware Ghashghaei in Matlab [9].

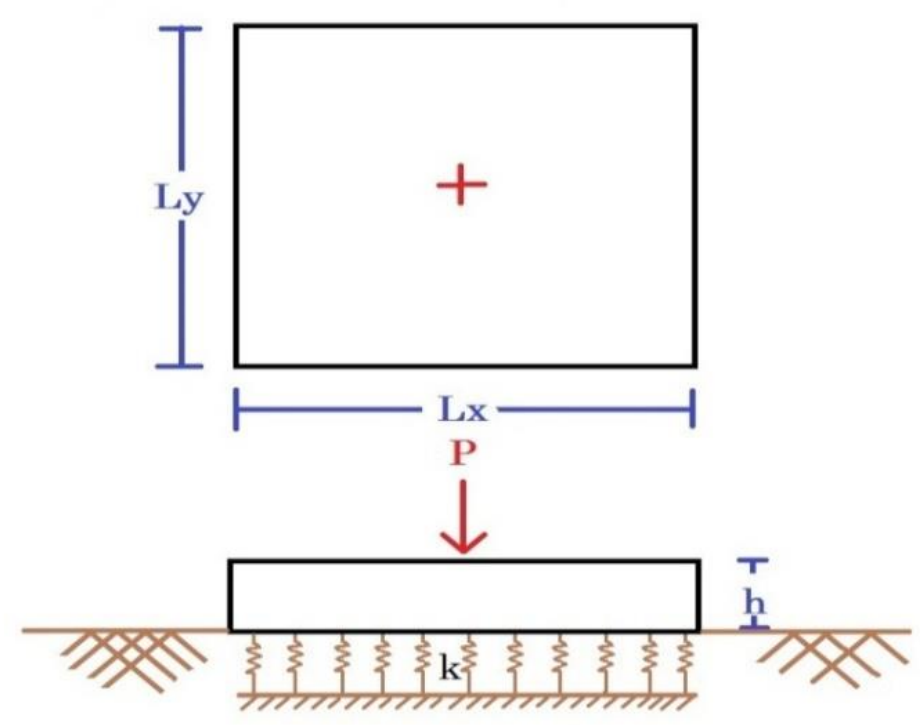

Fig. 2. Foundation foot on Winkler's springs with stiffness $k$

First example is an example of a foundation foot with the following characteristics:

$L_{x}=120 \mathrm{~cm}, L_{y}=120 \mathrm{~cm}, h=100 \mathrm{~cm}, E=2.1 \cdot 10^{5} M P a, v=0.20$,

and the results of calculations are represented with table 2 and figure 3 .

\begin{tabular}{|l|l|l|l|}
\hline Type of soil: & $k_{1}\left(10^{4} \mathrm{kN} / \mathrm{m}^{3}\right)$ & $k\left(10^{4} \mathrm{kN} / \mathrm{m}^{3}\right)$ & $\delta_{\max }(\mathrm{cm})$ \\
\hline Incoherent sand $($ dry or wet $)$ & 1.9 & 0.47975 & -3.353 \\
\hline Coherent sand $($ dry or wet $)$ & 32 & 8.08 & -2.321 \\
\hline Clay with stiff consistency & 2.4 & 0.606 & -3.326 \\
\hline Clay with solid consistency & 9.6 & 2.424 & -2.986 \\
\hline
\end{tabular}

Table 2. Results of settlement' calculations for foundation foot 

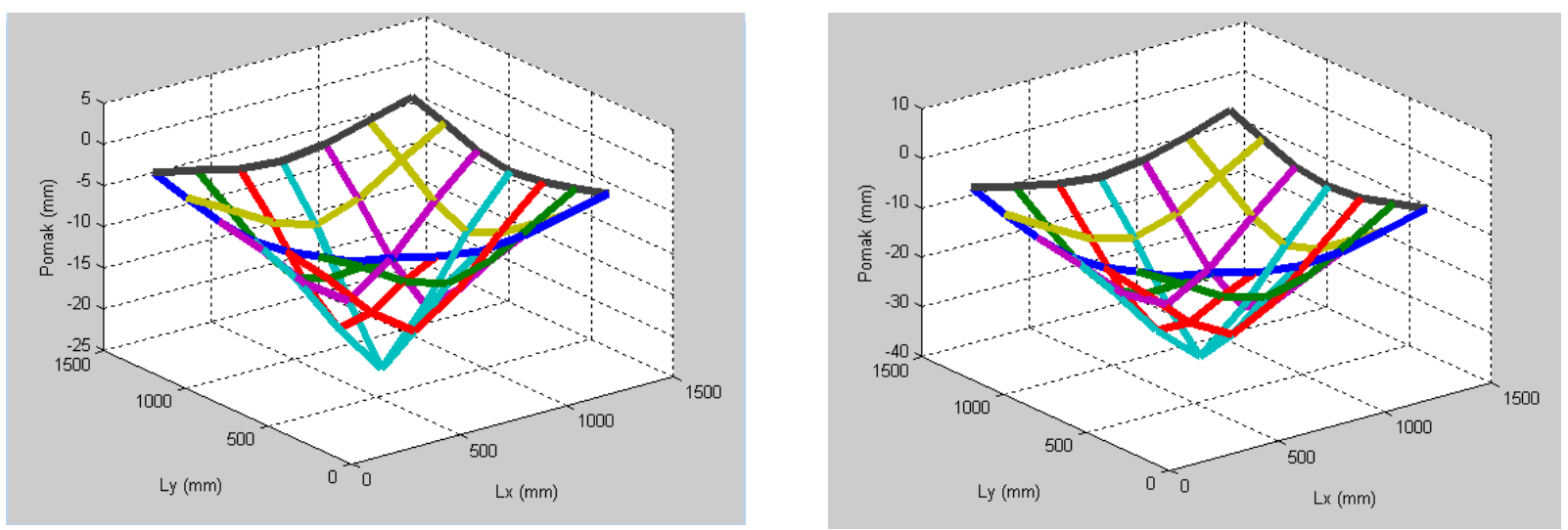

Fig. 3. Diagrams of deflections for foundation foot on elastic soil/base, obtained by finite difference method [9]

Second example is an example of a foundation plate, with dimension $500 \mathrm{~cm} \times 500 \mathrm{~cm}$, height $h=100 \mathrm{~cm}$, and with total load/force distributed symmetrically in four ultimate points of internal network. For this example, the results of calculations are represented with table 3 and figure 4.

\begin{tabular}{|l|l|l|l|}
\hline Type of soil: & $k_{1}\left(10^{4} \mathrm{kN} / \mathrm{m}^{3}\right)$ & $k\left(10^{4} \mathrm{kN} / \mathrm{m}^{3}\right)$ & $\delta_{\max }(\mathrm{cm})$ \\
\hline Incoherent sand $($ dry or wet) & 1.9 & 1279.3 & -2.06 \\
\hline Coherent sand $($ dry or wet) & 32 & 19392 & -1.55 \\
\hline Clay with stiff consistency & 2.4 & 14544 & -2.05 \\
\hline Clay with solid consistency & 9.6 & 5817.6 & -1.9 \\
\hline
\end{tabular}

Table 3. Results of settlement' calculations for foundation plate
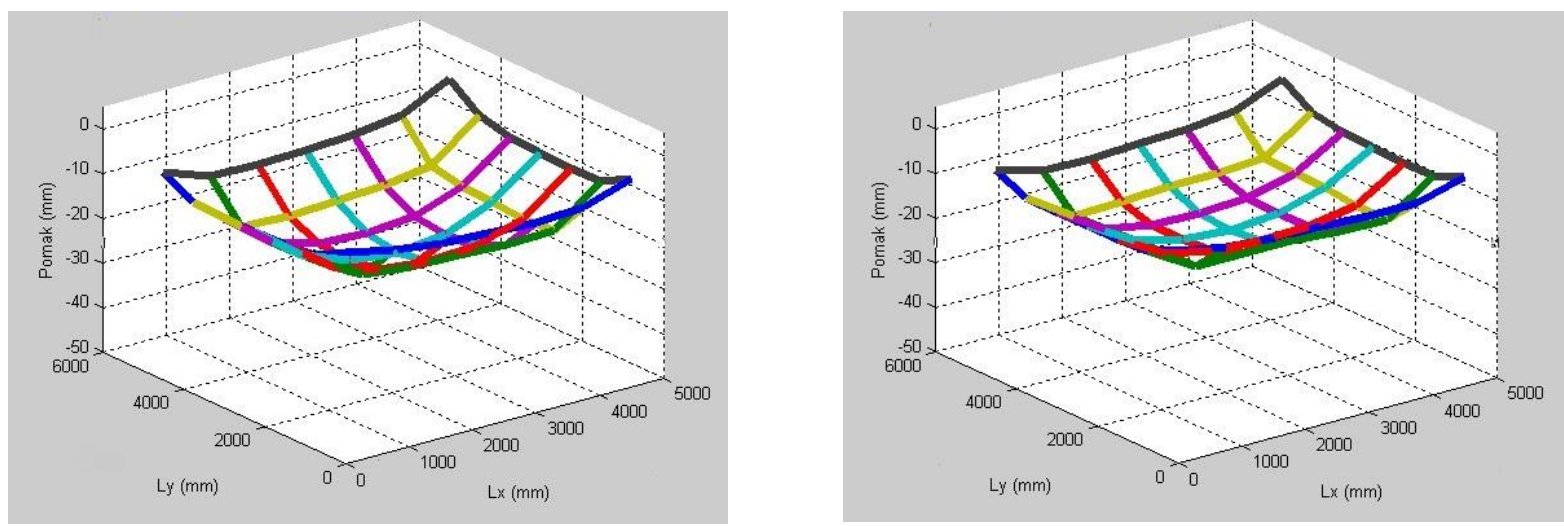

Fig. 4. Diagrams of deflections for foundation plate on elastic soil/base, obtained by finite difference method [9]

\section{Conclusion}

Examples of calculations for foundation plates, taken from practice and references, shows differences in accuracy for some numerical methods in the analysis of stresses and deformations/strains. In most of calculations the compressible soil is replaced with the system of elastic springs, which are deformed just below the loaded part of the plate. This model is not entirely satisfactory because deformations in real soil are spread beyond the loaded parts, but is still very widely used because the analytical solutions of differential equations is relatively simple, and the results are more realistic than those obtained with the assumption of linear distribution of soil reaction. Furthermore, in this model are not considered elongations (stresses) due to temperature.

By summarizing our results we obtain that finite difference method gives results similar to those obtained with the finite element method, but the contours of the bending moments obtained with finite difference method are less smooth than those obtained with finite element method. The density of the network has an impact on the results of each of the numerical methods. The higher density gives smoother diagrams of bending moments and deformation of the foundation plate. Our examples with calculations made by using modified Matlab program code, and their results, indicates that plate' settlement is less dependent on the change of modulus of soil reaction, as well as that the maximum values of those settlings are less than the values of settlings for foundation foot. These benefits and reduction of differential settlements are the most common reasons for selection of the foundation plate as a way of foundation of the building. The focus of further study has to be on including temperature strains, as well as dynamic load in calculations. 


\section{References}

[1] Hemsley, J. A. (2000). Design applications of raft foundations, Thomas Telford Publishing, London

[2] Moody, W. T. (1990). Moments and reactions for rectangular plates, U.S. Government Printing Office, Washington

[3] Scitovski, R. (2004). Numerical mathematics, Department of Mathematics, University of Osijek, ISBN 953-603224-4, Osijek

[4] Bowles, J. E. (1974). Analytic and computer methods in foundation engineering, McGraw-Hill Inc.,US, ISBN $978-$ 0070067530, New York

[5] Aron, C. \& Jonas, E. (2012). Structural element approaches for soil-structure interaction, M.Sc. Thesis, Department of Civil and Environmental Engineering, Chalmers University of Technology, Göteborg, Sweden

[6] Nonveiller, E. (1990). Soil mechanics and foundations of buildings, Školska knjiga, ISBN 978-8603996456, Zagreb

[7] Verić, F. (2000). Savitljive temeljne konstrukcije (Flexible foundation structure), Authorized lectures, Faculty of Civil Engineering, University of Zagreb, Institute of Geotechnics, Zagreb

[8] Roje-Bonacci, T. (2007). Posebna poglavlja temeljenja (Special chapters of foundation), Faculty of Civil Engineering and Architecture, University of Split, Split

[9] Matlab, The language of technical computing, http://www.mathworks.com/products/matlab/ 